\title{
THE INFLUENCE OF FLOODING RISK ON INFRASTRUCTURE DEVELOPMENT IN WESTERN SYDNEY \\ Professor Alan $\boldsymbol{P}$ Jeary and lan $\boldsymbol{P} \boldsymbol{M}$ Jeary, School of Construction, Property and Planning University of Western Sydney, New South Wales, Australia
}

\section{Introduction}

The city of Sydney boasts one of the greatest natural harbors in the world, and perception of the city tends to center on the business and harbor areas. However, the city limits are bounded to the west by the Blue Mountains, and to the north by the Hawkesbury river which flows out into the Tasman sea through a narrow opening between tall cliffs some $40 \mathrm{Km}$ north of the central business district. Rapid expansion has led to development of the western areas and in particular the vast flood plains that were previously used as arable or farming land. It has recently become apparent that the risks to the new populations were rising to unacceptable levels, and various limits on development were initiated. As part of the New South Wales government's strategy for disaster mitigation, in the event of a flood, great emphasis was placed on informing residents of areas likely to suffer inundation, and to prepare them for safe evacuation. The safe development of the Greater Western Sydney relies on the success of such plans.

In this study the authors have investigated the effect of the government initiatives on the local population, and have re-analysed the flood data for the last 200 years using the Lieblein Best Linear Unbiased Estimator (BLUE) technique. The results obtained have established more reliable estimates of the yearly flood probabilities and have highlighted the need for a greater effort from the New South Wales authorities to inform the residents of the area of the hazards posed by likely floods.

\section{The Context}

In the United States, in 1968, the National Flood Insurance Act was passed that required the President to report to Congress on progress towards achieving a "unified national program for floodplain management"(Johnston Associates, 1992). This was probably the first recognition worldwide that the management of floodplains, and their development for human usage, should combine development with an appreciation of natural resources and the importance of ecological resources. Such a wise recognition of the importance of natural resources was also appreciated in Australia, and in particular the approach was used in the Sydney basin.

The Hawkesbury river flows onto the western Sydney basin from the south, and is contained, just before the town of Wallacia, by the Warragamba Dam. Construction on the dam commenced in 1946 and was completed in 1960. In 1986 the New South Wales State government decided that, as a matter of policy, the flood plain "should not be unnecessarily sterilized and development should not be unreasonably restricted" ( Hawkesbury-Nepean Flood Management Committee, 1997).

In 1993 the State Government decided that the flood hazard would be significantly mitigated by raising the height of the Warragamba dam by 23 meters. However, a subsequent environmental impact study resulted in that plan not being carried through. Instead a new spillway was introduced together with usage plans intended to offset the effect of flooding. This spillway now assures the safety of the dam from collapse by overtopping, but does not significantly affect the risk of severe flooding in the downstream plains.

The topography of the area implies that it is highly likely that in the event of an extreme flood, towns in the area would first be isolated and then completely inundated. Under such a circumstance 
knowledge of the potential hazard by residents of extreme importance

It is clear that the chosen strategy is one in which, in the balance of competing risks, the requirements of the natural environment have gained ascendancy over the safety of human inhabitants of the Greater Western Sydney region. Under this circumstance the understanding of the risks involved, by the inhabitants, is of paramount importance. Indeed the strategy of the State Government of New South Wales includes the introduction of information channels to residents. Additionally some development control measures have been introduced into areas controlled by individual local councils.

As a result of this background it was decided that a study of a town in the middle of the region would be undertaken to ascertain whether or not the residents were fully aware of the issues involved in the potential for flooding of the area.

\section{The area of the study}

Situated near the center of the region under investigation is the town of Windsor. This is one of the five Macquarie towns initiated by one of the first governors of the new settlements in the late 18th century. The builders of the town recognized the danger of flooding and sited the new dwellings atop an outcrop near a bend in the Hawkesbury river. This outcrop rises to a height of a little more than 20 meters above the Australian Height Datum (AHD). Windsor, today, is still mainly located on the outcrop, although the town now counts a population of approximately 6,000 and has spread somewhat from its' early establishment. Areas of low-lying land, much of which is often under water, surround the town. The bridge at Windsor crosses the Hawkesbury river and represents a datum for the measurement of the height of flood waters. The bridge is 7 meters above the normal river level.
Over a period of several years' studies of rainfall runoff and stream flow computer models have been built up and used to model flooding behaviour in the region.

These studies have concentrated on benchmarking the 1867 flood. This was a major event in which water rose to 19 meters above the normal river level. This was 12 meters above the bridge at Windsor and 3.7 meters above today's urban development control level at Windsor

It is important to recognize that the 1867 event, though extreme, does not represent the maximum credible threat. An analytical study reported that the Probable maximum Flood (PMF) would result in floods to a depth of approximately 26 meters AHD, and that such an event would be likely to result in 60,000 evacuations and many deaths. The entire area would be disrupted for a period in excess of two years. The report estimates the annual probability of such an event as 1 in 100,000. A record of the depths to which flooding has occurred in the Windsor area is presented in Table 1, with depths noted relative to the Australian Height datum.

The statistics of flooding at Windsor

The data in table 1 were subjected to a Lieblein BLUE analysis (Lieblein, 1974). The results of such an analysis give a predictor for the event which has an annual probability of occurrence of 1 in 50 . The BLUE analysis gives more weight to the main body of the data, so that the estimates will not be unduly biased by an extreme event that occurs during the data collection period. For this particular data set, it is widely agreed that the PMF level approximately represents the 1 in 250 event. The data set has been collected for only 200 years and so the use of the BLUE analysis is favored here.

Theoretical Studies of flooding risk 


\section{Table 1 Floods recorded at Windsor (NSW)}

\begin{tabular}{|r|r|r|}
\hline Year & Month & $\begin{array}{r}\text { Height } \\
(\mathrm{m})\end{array}$ \\
\hline 1799 & 3 & 15.25 \\
\hline 1800 & 3 & 12.2 \\
\hline 1806 & 3 & 14.64 \\
\hline 1806 & 8 & 14.33 \\
\hline 1806 & 10 & 9.15 \\
\hline 1809 & 5 & 14.64 \\
\hline 1809 & 8 & 14.49 \\
\hline 1816 & 6 & 13.88 \\
\hline 1817 & 2 & 14.03 \\
\hline 1819 & 2 & 14.03 \\
\hline 1819 & 6 & 14.03 \\
\hline 1857 & 7 & 9.91 \\
\hline 1857 & 8 & 11.44 \\
\hline 1860 & 2 & 8.16 \\
\hline 1860 & 4 & 11.21 \\
\hline 1860 & 7 & 10.45 \\
\hline 1860 & 11 & 10.98 \\
\hline 1861 & 4 & 8.31 \\
\hline 1864 & 6 & 14.64 \\
\hline 1864 & 6 & 9.91 \\
\hline 1864 & 7 & 10.98 \\
\hline 1866 & 6 & 7.93 \\
\hline 1866 & 7 & 8.31 \\
\hline 1867 & 4 & 6.4 \\
\hline 1867 & 6 & 19.26 \\
\hline 1869 & 5 & 11.21 \\
\hline 1870 & 4 & 13.72 \\
\hline 1870 & 5 & 10.83 \\
\hline 1871 & 5 & 11.21 \\
\hline 1873 & 2 & 12.66 \\
\hline 1875 & 6 & 11.82 \\
\hline 1877 & 5 & 9.15 \\
\hline 1878 & 2 & 8.08 \\
\hline 1879 & 9 & 13.91 \\
\hline 1879 & 9 & 10.52 \\
\hline 1889 & 5 & 11.74 \\
\hline 1890 & 3 & 12.12 \\
\hline 1890 & 3 & 10.52 \\
\hline 1890 & 6 & 6.79 \\
\hline 1891 & 6 & 10.85 \\
\hline & & \\
\hline 18 & &
\end{tabular}

\begin{tabular}{|r|r|r|}
\hline 1892 & 9 & 8.08 \\
\hline 1893 & 3 & 8.62 \\
\hline 1894 & 3 & 9.68 \\
\hline 1895 & 1 & 9.3 \\
\hline 1897 & 7 & 6.86 \\
\hline 1898 & 2 & 9.61 \\
\hline 1899 & 8 & 8.08 \\
\hline 1899 & 8 & 6.71 \\
\hline 1900 & 7 & 14.08 \\
\hline 1904 & 7 & 12.22 \\
\hline 1910 & 7 & 6.4 \\
\hline 1911 & 1 & 7.85 \\
\hline 1912 & 7 & 6.71 \\
\hline 1912 & 8 & 7.32 \\
\hline 1913 & 5 & 8 \\
\hline 1915 & 1 & 7.62 \\
\hline 1916 & 10 & 10.83 \\
\hline 1922 & 7 & 9.45 \\
\hline 1925 & 5 & 7.62 \\
\hline 1925 & 6 & 11.36 \\
\hline 1934 & 2 & 9.15 \\
\hline 1942 & 3 & 6.25 \\
\hline 1942 & 10 & 7.37 \\
\hline 1943 & 5 & 10.11 \\
\hline 1949 & 1 & 7.32 \\
\hline 1949 & 6 & 11.97 \\
\hline 1950 & 3 & 9.2 \\
\hline 1950 & 4 & 9.2 \\
\hline 1950 & 4 & 8.54 \\
\hline 1950 & 5 & 7.32 \\
\hline 1950 & 6 & 9.45 \\
\hline 1950 & 6 & 7.55 \\
\hline 1950 & 6 & 7.34 \\
\hline 1950 & 6 & 7.32 \\
\hline 1951 & 1 & 8.97 \\
\hline 1951 & 6 & 7.17 \\
\hline 1951 & 9 & 6.71 \\
\hline 1952 & 6 & 9.35 \\
\hline 1952 & 7 & 11.61 \\
\hline 1952 & 8 & 9.71 \\
\hline 1952 & 8 & 8.77 \\
\hline 1955 & 5 & 9.76 \\
\hline & & \\
\hline 195 & & \\
\hline
\end{tabular}

\begin{tabular}{|c|c|c|}
\hline 1956 & 2 & 13.7 \\
\hline 1956 & 2 & 11.56 \\
\hline 1956 & 2 & 8.95 \\
\hline 1956 & 3 & 9.81 \\
\hline 1956 & 3 & 7.44 \\
\hline 1956 & 5 & 7.01 \\
\hline 1956 & 6 & 9.53 \\
\hline 1961 & 11 & 15.1 \\
\hline 1963 & 4 & 8.54 \\
\hline 1963 & 5 & 7.93 \\
\hline 1963 & 6 & 8.79 \\
\hline 1963 & 8 & 9.43 \\
\hline 1964 & 6 & 14.51 \\
\hline 1967 & 8 & 8.76 \\
\hline 1969 & 11 & 10.06 \\
\hline 1971 & 2 & 5.64 \\
\hline 1972 & 1 & 6.8 \\
\hline 1974 & 1 & 6.6 \\
\hline 1974 & 3 & 7.24 \\
\hline 1974 & 4 & 8.53 \\
\hline 1974 & 5 & 10.28 \\
\hline 1974 & 6 & 7.82 \\
\hline 1974 & 8 & 9.39 \\
\hline 1975 & 6 & 11.1 \\
\hline 1975 & 7 & 6.48 \\
\hline 1976 & 1 & 9.22 \\
\hline 1976 & 3 & 7.92 \\
\hline 1977 & 3 & 8.8 \\
\hline 1978 & 3 & 14.31 \\
\hline 1978 & 6 & 9.55 \\
\hline 1984 & 7 & 8.01 \\
\hline 1984 & 11 & 7.01 \\
\hline 1986 & 8 & 11.3 \\
\hline 1988 & 4 & 12.65 \\
\hline 1988 & 7 & 10.74 \\
\hline 1989 & 4 & 9.07 \\
\hline 1990 & 4 & 9.8 \\
\hline 1990 & 8 & 13.36 \\
\hline 1992 & 2 & 11 \\
\hline
\end{tabular}




\section{Table 2 Statistics relating to the depth of inundation at Windsor}

\begin{tabular}{|l|l|l|l|}
\hline $\begin{array}{l}\text { Annual } \\
\text { probability of } \\
\text { occurrence }\end{array}$ & BLUE & $\begin{array}{l}\text { Conventional } \\
\mathrm{H} 50=16.0\end{array}$ & $\begin{array}{l}\text { Conventional } \\
\mathrm{H} 50=17.6\end{array}$ \\
\hline 1 & 10.2 & 5.4 & 5.9 \\
\hline 10 & 15.0 & 12.8 & 14.0 \\
\hline 20 & 16.2 & 14.2 & 15.7 \\
\hline 50 & 17.6 & 16.0 & 17.6 \\
\hline 100 & 18.6 & 17.2 & 18.9 \\
\hline 200 & 19.5 & 18.3 & 20.2 \\
\hline 500 & 20.7 & 19.7 & 21.7 \\
\hline 1000 & 21.6 & 20.7 & 22.8 \\
\hline 10000 & 24.2 & 23.7 & 26.1 \\
\hline 100000 & 26.6 & 26.4 & ---- \\
\hline
\end{tabular}

In column 2 of the estimates (in table 2) the conventional approach has been fitted to the data published in a previous study. In this case the data fit the estimates for the 20,50,100 250 and 100,000 year events. This estimate also gives a more realistic estimate of the short duration events.

Data for return periods other than that for 50 years are calculated using a conversion factor of the form:

$$
S_{T}=\sqrt{\frac{n+\ln R}{n+\ln 50}}
$$

Where $S_{T}$ is the factor by which the 50 year event has to be multiplied to obtain the estimate for the once in $R$ years event. " $\mathrm{n}$ " is a factor determined by experiment. It's value lies between 0.5 and 5 .

In column 2 the data have been fitted using an appropriate value of ' $n$ '. Whilst, the estimate for the 1 in 50 year event is likely to be more precise using the BLUE analysis, it appears to overestimate the flood risk at very short return periods. Accordingly, the conventional methodology has been used to produce the return period risks in column 3 of Table 2, using a starting point of the 50 year prediction from the BLUE statistic. This column gives the estimates that are preferred by the authors because it combines the precision of the 1 in 50 year estimate with the lower level flooding for short return periods that correlate well with observation. The data from column 3 indicate that the inundation level for the 250-year event is greater and the risk of occurrence for the PMF is higher than had been previously thought.

These values should be considered in the light of the deck of the bridge at Windsor being 7 meters above the normal river level, and the limit of urban control of development being at 15.3 meters above the normal river level. No flood that has risen above the deck of the Windsor Bridge has occurred since 1990. Recent events in which the flood level was greater than 12 meters above the normal river level occurred in 1990, 1988, 1978 and 1964.

\section{Governmental Response to the risk}

As increased analysis capabilities have become available it has become apparent that the Warragamba dam could suffer damage or even collapse in the event of a very large flood. The implications for downstream populations are dire.

The New South Wales (NSW) government has proposed many solutions to this problem. In 1989 the dam height was increased by 5 meters and additional strengthening work was carried out. After 
the proposal to raise the height of the dam by a further 23 meters (referred to above) was turned down on environmental grounds the NSW Government set up the Hawkesbury-Nepean Flood Management Committee to advise on how best to deal with the risk. That committee produced a major report in 1997 and one year later work on an auxiliary spillway was started. This is due for completion in November 2001. The objective of the spillway is to allow sufficient run-off of flood water in the event of an extreme event, such that the dam would not be breached. This water would be released onto the floodplain.

The committee reported on a number of issues including engineering aspects, flood emergency plans, likely damage in floods and a review of public awareness.

In its' report the Hawkesbury-Nepean Flood Management Committee stated:

"Heightened public awareness is essential to generating the best public response to evacuation. Studies have shown that such public awareness 'reduces evacuation time, reduces actual flood damages (particularly commercial and industrial) and helps to reduce the post flood trauma of the affected population"

The cost of implementing such a strategy of communication was estimated to be between $\$ 0.5$ million and $\$ 1$ million annually.

\section{The Investigation}

Clearly, one of the main issues involving the security of residents of the floodplain in Western Sydney is the awareness of residents of the risk associated with flooding. Indeed the Hawkesbury-Nepean Flood Management Advisory Committee identified this factor as one of the most important for an effective community response to a large flood. As a result a survey was carried out in the Windsor area. The objective was to test the hypothesis:

"Residents of Windsor are not generally aware of the flood risk in the area."
The survey was applied by delivering questionnaires to a selection of houses in the area bounded by the 10 and 20 meter height (AHD) contours. The 20 meter height contour represents the limit of the area of inundation by the maximumrecorded flood in 1867 . The surveyed properties were therefore restricted to areas that would be inundated by levels of flooding up to 10 meters.

Stamped addressed return envelopes were included with the questionnaire. 100 questionnaires were delivered and the response rate was $33 \%$.

The purpose of this survey has been to see how effective the administration's efforts to raise public awareness of the flood risk have been.

For this purpose three questions were asked. The first question asked, "On average how often do you think your property might be affected by flooding". The purpose of this question was to determine what proportion of the population thought that flooding would never affect their property. Note that the recipients were asked if the flooding would affect their property. In fact properties would be affected by more than just water. The Hawkesbury-Nepean Flood Management Committee estimated that in the event of a repeat of the 1867 flood, properties would be subjected to loss of the electricity and water supplies, the appearance of raw sewage in the water and long-term disruption to the surrounding areas. Notwithstanding this scenario, the maximum credible flood for the area is a further 6.4 meters depth at a total of 26 meters AHD (Australian Height Datum).

The second question was intended to test the resident's knowledge of the height to which flood waters could rise. No reply of a flood level greater than 2 meters was received.

The third question asked whether the respondents were aware of floods having occurred in the area. 
It was assumed that the present community's experience was limited to the floods of 1964 (14.5 meters) and 1978 (14.3 meters). However, one 87-year-old respondent mentioned floods dating back to 1922 . Reference was also made by several respondents to the floods in 1964 in which the waters of the Hawkesbury river and South Creek (on opposite sides of Windsor, met in the main street of Windsor (George street). Residents gave much helpful information, and the authors are extremely grateful for their contributions.

The replies to the questionnaire and their significance are detailed below:

Question 1:

On average how often do you think your present property might be affected by flooding?

Respondents replied as follows:

\section{Table 3 Summary of responses about perceived flood risk recurrence}

\begin{tabular}{|l|c|l|l|}
\hline & $\begin{array}{c}\text { Frequency } \\
\%\end{array}$ & $\begin{array}{l}\text { Cumulative } \\
\text { percentage }\end{array}$ & $\begin{array}{l}\text { No. of } \\
\text { replies }\end{array}$ \\
\hline Never & 36.4 & 36.4 & 12 \\
\hline Every 1 year & 0.0 & 36.4 & 0 \\
\hline Every 2 years & 6.1 & 42.4 & 2 \\
\hline Every 10 years & 12.1 & 54.6 & 4 \\
\hline Every 50 years & 9.1 & 63.6 & 3 \\
\hline Every 100 years & 27.3 & 90.9 & 9 \\
\hline Every 250 years & 9.1 & 100.0 & 3 \\
\hline
\end{tabular}

The Hawkesbury-Nepean Flood Management Committee estimates that for the Windsor area electricity would be disrupted for 2 days to one week for a 1 in 10 year flood. At the 1 in 50 year level of flood both telecommunications and gas would be lost and electricity would be lost for up to six months. For the 1 in 500 year flood raw sewage would appear in the water.

The implication of the results of the survey is that $54.6 \%(+/-6.6 \%)$ of residents in Windsor are aware of the true risk of disruption caused by flooding.

Probably of even more significance is that more than 1 in 3 residents do not appear to think that there is any risk of disruption whatsoever.

Question 2

This question asked:
How high up your house would you expect the water to rise?

23 replies were received. 10 respondents gave no reply to this question.

19 respondents thought that the flood waters would rise to less than 1 meter, whilst 4 thought that the waters might rise to as much as 2 meters.

For the Maximum Credible Flood the flood waters would rise to inundate all of Windsor. The level of flooding in some of the surveyed houses would be as much as 8 meters (e.g. Mileham Street).

However, residents clearly associated the maximum risk with a level of flooding that is a risk level somewhere between the 20 and 50 year return periods. Interestingly, this would correlate with the memory of current residents.

Question 3 asked: 
Are you aware of any floods in the history of your area?

All 33 respondents replied to this question with 29 indicating that they were aware of floods and 4 people not being aware of any floods in the area. This represents $12 \%(+/-1.4 \%)$ of the surveyed population not being aware of historical floods in the area. The last major flood was in August 1990 when the height of flooding was 13.4 meters (approximately the 1 in 10 year return height).

Other comments to come out of the survey were as follows:

One respondent had been sensitized to the risk of flooding by having been resident in Katherine when the Australia day floods occurred there. One resident reported this as being the longest period without flooding in their memory. This was a period of greater than 8 years. The average was reported as being one every three years.

One resident helpfully noted the height of their curb above the mean water mark of the river.

One long term resident of the region supplied detailed lists of floods through the last 200 years and a cutting from a newspaper dated June 16th 1995 detailing the flood evacuation plans for the area. This particular person phoned and supplied a great deal of extremely useful information.

One respondent living in South Windsor reported that the 1964 flood came close to that particular residence. They reported that as far as they knew they were out of the flood area.

One respondent reported that in the 1964 flood when the waters met at the bottom of George Street their property on higher ground was not affected. This respondent also reported that the 1867 flood was the only one known to affect their property.

\section{Significance}

33 replies were received. The population of Windsor is approximately 6,000 (source: Australian Bureau of Statistics 1996 census). This means that at the 95\% confidence level results are accurate to within $12 \%$ for results evenly split between positive and negative replies. Results in which there is other than a $50-50$ split give a slightly better accuracy.

\section{Comments}

The implications from the study are the following:

Approximately half of the population of Windsor is unaware that flooding in their area is likely to affect them with a $10 \%$ probability of occurrence each year (1 in 10 year event).

Residents of Windsor are generally unaware of the risks posed by the maximum credible flood in the area (at the $99 \%$ confidence level).

Approximately $60 \%$ of residents were aware of the risk of flooding, but assumed that the level of flooding would be restricted to the same as in the flood of 1867.

A worryingly large percentage of respondents $(12 \%)$ think that there is no risk of flooding at all in the Windsor area.

It is clear from the study that government campaigns for public awareness of the risks posed by flooding in the Windsor area have not yet had the required effect. Whilst there is a considerable amount of knowledge within the Windsor community about the risk of flooding and of the historical effects of flooding (including the 1867 flood), there is almost no perception that greater floods are possible. (Such flooding may even become more probable with more human development of the land).

\section{Conclusions}

The hypothesis tested has been accepted at the $95 \%$ confidence level. This implies that the main governmental strategy for 
mitigating flood damage through passing information to residents has not been effectively implemented.

Additionally, whilst there is considerable knowledge about flooding within the community at Windsor, the limit of resident's memories tends to limit the perception of risk.

Finally, there is almost no perception of the risk of the maximum credible flood (tested at the 99\% confidence level).

Put another way, any attempts by government to make the public aware of the flood risk in Windsor have not been completely effective. In particular approximately $10 \%$ of the population is completely unaware of the risk of any type of flooding, approximately half of the population is aware that flooding (even at lower levels) may affect their, and all of the population is unaware of the risk posed by the maximum credible flood.

\section{Discussion}

Residents, in the Windsor region, appear to be working on the same assumption as did Governor Macquarie when he founded the settlement, in that they assume that the siting of the town on a ridge gives complete protection against flooding. The New South Wales government response has followed the model developed in the USA in attempting to use a wider concept towards the mitigation of risk. This concept adopts a wide view of human settlement and addresses concepts of humankind's place on the planet. As a result risks are taken that would be avoided using the older style of engineered approach. However, a vital constituent of this approach is to inform those at risk of the dangers. Indeed the NSW government's approach recognized this factor and assessed its implementation cost. It is apparent from this study, that the government information schedule has been ineffective in making residents of the Windsor region aware of the risks run by living in the area. As a result, the risk to the settled population is greater because the lack of an appreciation of risk would be likely to lead to a slower response time in the event of danger. In turn this would be likely to lead to greater injury and loss of life than is achievable when the extreme events occur. It is recommended that authorities should revisit the question of sensitizing the population to the risk and to means of escape in the event of a flood that exceeds the community memory.

\section{Acknowledgements}

The authors gratefully acknowledge the information supplied by several people. In particular, maps and information supplied by Ms. J. Stephens is gratefully acknowledged.

A small grant to enable the survey to be carried out from Structural Survey Hong Kong Ltd. is gratefully acknowledged.

\section{References}

1. L.R. Johnston Associates, 1992: Floodplain Management in the United States: An assessment report. Contract No. TV-72105A for the Interagency Floodplain Management Taskforce.

\section{Hawkesbury-Nepean Flood} Management Committee, 1997: Achieving a Hawkesbury-Nepean Floodplain Management Strategy. ISBN 073130342 3.

3. Lieblein J., 1974: Efficient Methods of Extreme Value Methodology. National Bureau of Standards, Washington. Technical Analysis Division. NBSIR 74602. 